$\begin{array}{cl}\begin{array}{c}\text { Revue } \\ \text { de /histoire }\end{array} & \text { Revue de l'histoire des religions } \\ \text { des religions } & \begin{array}{l}3 \mid 2012 \\ \text { Varia }\end{array}\end{array}$

\title{
Des églises byzantines converties à l'islam ? Quelques mosquées ibadites du djebel Nafûsa (Libye)
}

Byzantine Churches Converted to Islam? Some Ibadi Mosques of the Jebel Nafûsa (Libya)

\section{Virginie Prevost}

URL : http://journals.openedition.org/rhr/7905

DOI : $10.4000 /$ rhr 7905

ISSN : 2105-2573

Éditeur

Armand Colin

\section{Édition imprimée}

Date de publication : 1 septembre 2012

Pagination : 325-347

ISBN : 978-2200-92975-0

ISSN : 0035-1423

\section{Référence électronique}

Virginie Prevost, « Des églises byzantines converties à l'islam ? Quelques mosquées ibadites du djebel Nafûsa (Libye) ", Revue de l'histoire des religions [En ligne], 3 | 2012, mis en ligne le 01 septembre 2015, consulté le 06 mai 2019. URL : http://journals.openedition.org/rhr/7905 ; DOI : 10.4000/rhr.7905 


\title{
Des églises byzantines converties à l'islam ? Quelques mosquées ibadites du djebel Nafûsa (Libye)
}

\begin{abstract}
La population berbère du djebel Nafûsa était majoritairement chrétienne lorsqu'elle a adopté massivement la doctrine ibadite à la fin de la première moitié du vIII siècle. Cette région conserve de nombreuses mosquées qui portent des noms associés au christianisme, qui font référence aux apôtres ou sont directement issus du latin ecclesia. Les sources ibadites laissent penser qu'il s'agit d'églises byzantines reconverties en mosquées. Cependant, si l'origine chrétienne du bâtiment apparaît distinctement dans un des exemples étudiés, la plupart de ces mosquées n'ont sans doute aucun lien avec d'anciennes églises. Leur nom évoque simplement le souvenir du passé chrétien de la région.
\end{abstract}

\section{Byzantine Churches Converted to Islam? Some Ibadi Mosques of the Jebel Nafûsa (Libya)}

The majority of the Berbers of Jebel Nafûsa were Christian when they overwhelmingly adopted the Ibadi doctrine at the end of the first half of the eighth century. This region still contains numerous mosques which bear names with Christian connotations, referring to the apostles or evidently derived from the Latin ecclesia. The Ibadi sources lead us to believe that they are Byzantine churches transformed into mosques. However, if the Christian origin of the building obviously appears in one of the examples visited, most of the other mosques have without a doubt no link with old churches. Their names only recall the memory of the Christian past of the region. 
Dans un précédent article, nous avons évoqué les bonnes relations qu'ont généralement entretenues les communautés chrétiennes d'Afrique du Nord avec les musulmans ibadites ${ }^{1}$. Ainsi Tâhart, la capitale des imams rustumides, offrait aux chrétiens une place privilégiée; selon Ibn al-Ṣaghîr, l'endroit le plus haut de la ville s'appelait «al-kanîsa», c'est-à-dire l'église ${ }^{2}$. Cette église, et le quartier chrétien qui l'entourait sans doute, devaient se situer non loin de la citadelle dans laquelle vivait l'imam ibadite ${ }^{3}$. Lorsque Tâhart tomba en 909 aux mains des armées chiites qui allaient porter au pouvoir le premier souverain fatimide, un groupe de chrétiens accompagna le dernier imam dans la région de Ouargla où les ibadites fondèrent une nouvelle capitale, Sadrâta, qu'ils occupèrent avant d'aller s'installer au $\mathrm{XI}^{\mathrm{e}}$ siècle dans le Mzab. Nous avons souligné l'influence que le christianisme a eue sur l'ibadisme, tant du point de vue artistique - comme on peut le constater dans les vestiges de Sadrâta - que du point de vue religieux, sachant que les deux doctrines partageaient certaines valeurs communes. Enfin, nous avons fait remarquer que les ibadites n'ont pas hésité à convertir les anciennes églises à leur propre culte, spécialement dans le djebel Nafûsa. C'est à ce sujet que nous nous intéresserons dans les pages qui suivent.

Le géographe al-Bakrî, rapportant des renseignements datant de la seconde moitié $\mathrm{du} \mathrm{x}^{\mathrm{e}}$ siècle, décrit brièvement le djebel Nafûsa dont la longueur d'est en ouest correspond à six jours de marche. Il évoque la ville de Jâdû, habitée par de nombreux juifs, et celle de Sharûs, la principale ville de ces montagnes, peuplée majoritairement d'ibadites. Il précise que les Nafûsa étaient chrétiens lorsqu'ils ont été soumis par le général arabe 'Amr ibn al- 'Âṣ ${ }^{4}$. Les Berbères Nafûsa, qui correspondraient aux Naffur

1. Virginie Prevost, «Les dernières communautés chrétiennes autochtones d'Afrique du Nord», Revue de l'histoire des religions, 224/4 (2007), p. 461-468.

2. Ibn al-Saghîr, Akhbâr al-a'imma l-rustumiyyîn, éd. Muhammad Nâșir et Ibrâhîm Baḥhâz, Beyrouth, Dâr al-gharb al-islâmî, 1986, p. 79.

3. Georges Marçais et Alfred Dessus-Lamare, «Tîhert - Tagdempt», Revue Africaine, XC (1946), p. 42.

4. Al-Bakrî, Kitâb al-Mughrib fî̀ dhikr bilâd Ifrîqiya wa-l-Maghrib; Description de l'Afrique septentrionale, éd. trad. William Mac Guckin de Slane, Paris, Jean Maisonneuve, 1965, p. 9/p. 25-26. 
évoqués par Corippe ${ }^{5}$, vivaient principalement dans le djebel auquel ils ont donné leur nom et dans la plaine de la Jaffâra qui sépare ces montagnes de la Méditerranée. Ils entretenaient manifestement des rapports avec les cités chrétiennes de la côte, notamment avec l'importante ville de Sabratha qui était l'un des cinq sièges épiscopaux tripolitains. De Sabratha partait la piste caravanière qui menait à Cydamus, l'actuelle Ghadamès, en traversant le djebel, ce qui favorisa certainement une christianisation rapide des montagnes. En effet, le De Aedificiis de Procope établit que les habitants de Cydamus se convertirent au christianisme avant 558 environ, date de l'ouvrage; les missions chrétiennes venues de Sabratha étaient obligatoirement passées par le djebel ${ }^{6}$. Ibn Khaldûn affirme qu'avant la conquête arabe, Șabra (Sabratha) était un des domiciles des Nafûsa ${ }^{7}$. Ils furent donc, à l'avis de Tadeusz Lewicki, soumis directement à la propagande chrétienne ${ }^{8}$. Le djebel présente des traces de christianisation antérieures au $\mathrm{VI}^{\mathrm{e}}$ siècle - l'église d'el-Asabaa daterait dans sa première forme de la fin du $\mathrm{IV}^{\mathrm{e}} \mathrm{ou}$ du $\mathrm{V}^{\mathrm{e}}$ siècle - mais il apparaît que le mouvement s'est surtout intensifié après la reconquête byzantine du $\mathrm{VI}^{\mathrm{e}}$ siècle, époque à laquelle peuvent être rattachés la plupart des lieux de culte mis au jour ${ }^{9}$. Il faut noter que la population chrétienne du djebel se partageait entre chrétiens orthodoxes et dissidents; en effet, le schisme donatiste y avait une grande importance ${ }^{10}$. Le village ibadite d'Îdûnât, déjà habité sous les Romains, semble devoir son nom à un groupe de donatistes qui se seraient réfugiés là $\mathrm{au} \mathrm{IV}^{\mathrm{e}}$ siècle pour fuir la répression de l'orthodoxie chrétienne ${ }^{11}$.

5. Yves Modéran, Les Maures et l'Afrique romaine (IV ${ }^{e}-V I I^{e}$ siècle), Rome, École française de Rome, 2003, p. 104-107.

6. Tadeusz Lewicki, Études ibâdites nord-africaines, Varsovie, Państwowe Wydawnictwo Naukowe, 1955, p. 52-53.

7. Ibn Khaldûn, Kitâb al-'Ibar, Beyrouth, Dâr al-kutub al-'ilmiyya, 1992, VI, p. 134; Histoire des Berbères et des dynasties musulmanes de l'Afrique septentrionale, trad. William Mac Guckin de Slane, Paris, Paul Geuthner, rééd. 1999, I, p. 226-227.

8. T. Lewicki, Études ibâdites nord-africaines, p. 54.

9. Y. Modéran, Les Maures et l'Afrique romaine, p. 654.

10. Antonino Di Vita, «La diffusion del cristianesimo nell'interno della Tripolitania», Quaderni di archeologia della Libia, 5 (1967), p. 122.

11. T. Lewicki, Études ibâdites nord-africaines, p. 39 et p. 51. Al-Bughtûrî (Maqrîn ibn Muhammad), Sîra mashâ'ikh Nafûsa, éd. Tawfîq 'Ayyâd al-Shaqrûnî, s.l., Mu'assasa Tâwâlt al-thaqâfiyya, 2009, p. 123 et al-Shammâkhî, Kitâb al-Siyar, 
Les Arabes dirigés par 'Amr ibn al- 'Âṣ conquièrent Tripoli et sa région en 643 ou en $644^{12}$. Lors de l' attaque de Tripoli, les Byzantins demandent l'aide des Nafûsa qui sont chrétiens comme eux ${ }^{13}$. Après la prise de Tripoli, les Arabes pillent la ville de Sabratha et il semble bien qu'ensuite, 'Amr ibn al- 'Âs conquiert le djebel Nafûsa ou qu'il y fait tout au moins une incursion victorieuse ${ }^{14}$. Privés de leur résidence de Sabratha, fuyant les armées arabes qui tiennent la côte, tout porte à croire que les Nafûsa se retirent alors dans les montagnes ${ }^{15}$. Comme le souligne Yves Modéran, nous n'avons aucun indice d'un quelconque soulèvement des Nafûsa entre cette époque et les premiers troubles khârijites survenant dans les années 740 ; cet historien en déduit que le phénomène de conversion à l'islam a dû commencer, même s'il a été lent, dès 643 et qu'il «serait très abusif de considérer globalement, comme on semble parfois le faire, les Nafûsa entre 643 et 741-742 comme un bloc de Berbères à la fois chrétiens et hostiles aux Arabes ${ }^{16}$. Tout au contraire, Tadeusz Lewicki estime que les Nafûsa restent chrétiens pendant encore environ un siècle, par opposition aux gouverneurs arabes; vers 740, au contact des premiers dissidents khârijites dont la révolte contre l'occupant est beaucoup plus active que l'opposition pacifique des chrétiens, ils abandonnent le christianisme pour le khârijisme, sans passer par l'étape sunnite, dans le but d'affirmer leur particularisme berbère vis-à-vis des Arabes ${ }^{17}$.

Suivant l'historien ibadite Ibn Sallâm, c'est 'Umar ibn Îmkatan qui, le premier, enseigna le Coran dans le djebel Nafûsa. Il l'étudia en se rendant à plusieurs reprises sur la route de Maghmadâs, la

éd. Muhammad Hasan, Beyrouth, Dâr al-madâr al-islâmî, 2009, p. 375 et p. 386, l'évoquent sous la forme Idûnât ou Adûnâț.

12. Sur la conquête de la Tripolitaine, voir Jacques Thiry, Le Sahara libyen dans l'Afrique du Nord médiévale, Louvain, Peeters, 1995, p. 59-61.

13. Ibn 'Idhârî, Al-Bayân al-mughrib fì akhbâr al-Andalus wa-l-Maghrib, éd. Georges Séraphin Colin et Évariste Lévi-Provençal, Beyrouth, Al-dâr al-‘arabiyya li-l-kitâb, 1983, I, p. 8.

14. J. Thiry, Le Sahara libyen, p. 60-61.

15. Francesco Beguinot, Encyclopédie de l'Islam, $2^{\mathrm{e}}$ éd., s.v. Nafûsa, souligne toutefois qu'une partie des Nafûsa ont dû rester dans leurs anciens habitats, se mêler par mariage à d'autres tribus et s'arabiser avec le temps.

16. Y. Modéran, Les Maures et l'Afrique romaine, p. 783-784. Sur la conversion des Berbères à l'islam et les premières révoltes khârijites, voir V. Prevost, L'aventure ibâdite dans le Sud tunisien. Effervescence d'une région те́сопnиe, Helsinki, Academia Scientiarum Fennica, 2008, p. 50-67.

17. T. Lewicki, Études ibâdites nord-africaines, p. 54-55. 
grande voie qui longe la côte libyenne, empruntée par une foule de commerçants et de voyageurs venus d'Orient. À force de recopier les versets sur des tablettes et de les mémoriser, il apprit par cœur le Coran tout entier. La science religieuse lui fut également enseignée par les voyageurs ibadites ${ }^{18}$. On ne peut dater précisément l'enseignement que délivre 'Umar ibn Îmkatan mais il apparaît que le djebel est déjà largement conquis à la doctrine ibadite au milieu du VIII ${ }^{\mathrm{e}}$ siècle. En 132/749-750 en effet, c'est un chef issu des Nafûsa, Ismâ'îl ibn Ziyâd al-Nafûsî, qui est élu imam par les ibadites de Tripolitaine; il est toutefois très rapidement vaincu par le gouverneur omeyyade d'Ifrîqiya ${ }^{19}$. C'est manifestement après cette défaite que plusieurs missionnaires maghrébins se rendent à Bașra en Irak pour étudier l'ibadisme auprès du grand savant Abû 'Ubayda Muslim al-Tamîmî. Cinq d'entre eux, connus sous le nom de «porteurs de science» reviennent au Maghreb peu avant 140/757-758, date à laquelle ils proclament Abû l-Khatțâb al-Ma âfirîi imam ${ }^{20}$. Si l'on en croit les sources ibadites, un des missionnaires partis s'instruire en Orient, toutefois, revient au Maghreb avant eux : c'est un Berbère de la tribu des Nafûsa nommé Ibn Maghtị̂r al-Nafûsî al-Janâwunî qui, fort de ses études à Baṣra, est devenu mufti dans le djebel ${ }^{21}$.

18. 'Umar ibn Îmkatan mourut en martyr aux côtés de l'imam ibadite Abû 1-Khatțâb al-Ma'âfirî en 144/761. Ibn Sallâm, Kitâb Ibn Sallâm: Eine IbaditischMaghribinische Geschichte des Islams aus dem 3./9. Jahrundert, éd. Werner Schwartz et Sâlim ibn Ya'qûb, Wiesbaden, Franz Steiner Verlag, 1986, p. 125126; al-Shammâkhî, op. cit., p. 268-269. Selon T. Lewicki, «Les noms propres berbères employés chez les Nafûsa médiévaux $\left(\mathrm{VIIII}^{\mathrm{e}}-\mathrm{XVI}^{\mathrm{e}}\right.$ siècle). Observations d'un arabisant (4)», Folia Orientalia, XXVII (1990), p. 121, le nom «Îmkatan» est un pluriel masculin berbère d'un singulier MKT ou MGT que l'on rencontre dans l'Afrique romaine, par exemple dans l'inscription latine évoquant un certain Megethus ou dans le personnage nommé Maggite Maurus cité par Corippe.

19. Ibn 'Abd al-Hakam, Futûh Mișr, The History of the Conquest of Egypt, North Africa and Spain, éd. Charles C. Torrey, New Haven, Yale University Press, 1922, p. 225; Ibn Khaldûn, op. cit., éd. VI, p. 135/trad. I, p. 227.

20. Sur les «porteurs de science», Abû Zakariyyâ' (al-Wârjalânî), Kitâb al-Sîra wa-akhbâr al-a'imma, éd. 'Abd al-Rahmân Ayyûb, Tunis, Al-dâr al-tûnisiyya li-lnashr, 1985, p. 57-58; al-Bughțûrî, op. cit., p. 29-30; al-Darjînî, Kitâb Tabaqât al-mashâ'ikh bi-l-Maghrib, éd. Ibrâhîm Țallây, Constantine, Maṭba'at al-ba'th, 1974, p. 19; al-Shammâkhî, op. cit., p. 246 et p. 268.

21. Al-Bughtûrî, op. cit., p. 124; al-Shammâkhî, op. cit., p. 270-271. Ibn Maghtîr est également mentionné comme étant celui qui a précédé les cinq «porteurs de science» dans un ouvrage ibadite anonyme, connu sous le nom de Siyar al-mashâ'ikh, p. 544. Ce texte, vraisemblablement rédigé dans la seconde moitié du XII ${ }^{\mathrm{e}}$ siècle, vient d'être édité pour la première fois, attribué erronément à al-Wisyânî, dans Siyar al-Wisyânî, éd. 'Umar ibn Luqmân Ḥammû Sulaymân 
Selon les sources ibadites, les Nafûsa sont donc confrontés, avant le retour des «porteurs de science», à deux enseignements différents, celui de 'Umar ibn Îmkatan acquis au contact des voyageurs et celui d'Ibn Maghtîr reçu à Bașra. Elles ne laissent aucun doute sur le fait que les Nafûsa adoptent avec enthousiasme cette foi nouvelle et n'évoquent pas l'enseignement d'un islam orthodoxe au cœur des montagnes. Ainsi, les sources ibadites confortent la thèse de Tadeusz Lewicki selon laquelle les Nafûsa passent directement du christianisme à l'ibadisme. Les Berbères de cette région demeurent ensuite ibadites dans leur grande majorité. Aujourd'hui, suite à une importante répression du régime libyen, l'ibadisme y est sans doute en déclin mais il faut noter qu'à la fin du XIX ${ }^{\mathrm{e}}$ siècle, le djebel Nafûsa est encore considéré par les Mozabites «comme une région sainte; il est toujours pour eux le fort de l'ibadisme en Afrique ${ }^{22}$.

Les sources relatives aux endroits vénérés du djebel Nafûsa mentionnent plusieurs mosquées qui sont dites apostoliques ou qui ont conservé leur nom d'église (kanîsa). L'historien ibadite al-Shammâkhî (m. 1522) affirme qu'il y avait dans le djebel onze mosquées attribuées aux apôtres (hawâriyyûn), dont la mosquée de Tukît ou Tûkît ${ }^{23}$. Ces mosquées apostoliques étaient considérées au $\mathrm{XVI}^{\mathrm{e}}$ siècle comme des églises chrétiennes de l'époque des apôtres, transformées en mosquées ${ }^{24}$. La liste ibadite nommée Tasmiya mashâhid al-jabal ${ }^{25}$, qui constitue une sorte de guide pour les pèlerins qui visitent les lieux sacrés de ces montagnes, mentionne huit kanîsa ou églises, qui correspondent très certainement aux mosquées apostoliques évoquées par al-Shammâkhîi ${ }^{26}$. Enfin, la

Bû 'Așbâna, Mascate, Wizârat al-turâth wa-l-thaqâfa, 2009, II, pp. 517-761. Abû Zakariyyâ', op. cit., p. 117-118, évoque seulement son rôle d'arbitre auprès de l'imam 'Abd al-Wahhâb lorsque ce dernier séjourne dans le djebel vers 810 . Le nom d'Ibn Maghṭ̂r provient peut-être d'une légère déformation du mot latin «martyr» devenu un nom propre chrétien. T. Lewicki, Études ibâdites nordafricaines, p. 93.

22. Adolphe de Calassanti Motylinski, Le Djebel Nefousa, Paris, Ernest Leroux, 1898, p. V.

23. Al-Shammâkhî, op. cit., p. 803.

24. T. Lewicki, Études ibâdites nord-africaines, p. 36.

25. Si René Basset qui a publié la liste la date du XVI $I^{\mathrm{e}}$ siècle, Tadeusz Lewicki pense qu'elle a été rédigée sans doute au $\mathrm{XIV}^{\mathrm{e}}$ ou au $\mathrm{XV}^{\mathrm{e}}$ siècle par un certain Abû 'Imrân Mûsâ al-Shammâkhî, grand connaisseur de mosquées et de tombeaux, qui mourut vers 1405 . T. Lewicki, «Les sources ibâdites de l'histoire médiévale de l'Afrique du Nord», Africana Bulletin, XXXV (1988), p. 38-39.

26. René Basset, «Les sanctuaires du Djebel Nefousa», réimpr. in Cahiers de 
description du djebel Nafûsa rédigée en berbère à la fin du XIX ${ }^{\mathrm{e}}$ siècle par Brâhîm ibn Slîmân al-Shammâkhî, à la demande d'Adolphe de Callasanti Motylinski, signale quatre mosquées dites apostoliques, peut-être cinq car les indications concernant Temezda (Tamazdâ) ne sont pas suffisamment claires pour établir s'il existait là une ou deux mosquées de ce type ${ }^{27}$. Entre 1969 et 1973, trois missions américaines successives ont pu étudier dans le djebel Nafûsa trois mosquées «apostoliques», une kanîsa et trois mosquées nommées Taghlîs, un nom dérivé d'ecclesia ${ }^{28}$. En 1981, une thèse de doctorat sur l'architecture islamique du djebel a été défendue à Londres par un chercheur libyen, Muḥammad al-Warfallî. Depuis lors, à notre connaissance, plus aucun document important n'a été publié sur les mosquées du djebel. Connaissant la situation pénible que vivent les ibadites sous le régime du colonel Kadhafi et soupçonnant la disparition progressive d'un grand nombre de mosquées, il nous a paru intéressant de partir à la recherche de ces vieilles églises byzantines converties à l'ibadisme. Ce voyage a pu être organisé en mai 2010, en compagnie du photographe Axel Derriks. Grâce à la documentation que nous avions préalablement rassemblée, à la bonne volonté inattendue de l'escorte imposée par le régime libyen et surtout au concours généreux des ibadites rencontrés sur place, nous avons pu retrouver quatre des anciennes églises mentionnées plus haut.

\section{LA MOSQuÉE HạÂÂRIYYîn dE TAMAZDÂ}

Elle se trouve isolée dans les environs de Tamazdâ, à l'ouest de Jâdû. Le village de Tamazdâ est déjà évoqué à propos d'événements

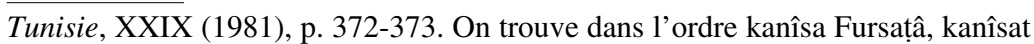
al-Jazîra, kanîsa Bughtûra, kanîsa Tinbatîn, kanîsat Aghramînân, kanîsa Tamazdâ, kanîsa Tûkît et kanîsa Masîn. L'église de Tûkît correspond certainement à la mosquée du même nom, remontant aux apôtres, évoquée par al-Shammâkhî, $o p$. cit., p. 803.

27. A. Motylinski, Le Djebel Nefousa, p. 74 (mosquée apostolique de Tazurayt), p. 75 (mosquée dite des apôtres à Taghma), p. 86 (la mosquée dite apostolique de Ṭarmisa) et p. 93 (à Temezda, une mosquée apostolique (et?) la grande mosquée apostolique d'origine antique).

28. James W. Allan, «Some Mosques of the Jebel Nafusa», Libya Antiqua, IX-X (1972-1973), p. 168-169. 
qui se déroulent au début du $\mathrm{IX}^{\mathrm{e}}$ siècle $^{29}$. La mosquée Ḥawâriyyîn a été étudiée vers 1970 par les archéologues américains, qui décrivent brièvement un édifice d'environ 12,8 x 8,7 mètres, formé de trois nefs séparées par des arcades, présentant un mihrab saillant et un décor intérieur en mauvais état fait de motifs et d'inscriptions. Ils notent que la mosquée a récemment été blanchie à la chaux. Les deux photos intérieur et extérieur font voir un édifice en bon état de conservation $^{30}$. Tout au contraire, nous avons trouvé une mosquée partiellement en ruine, dont une partie du toit s'est effondrée et dont le sol est couvert de gravats (ill. 1 et 2). La niche du mihrab est en voie d'éboulement et les inscriptions ont manifestement disparu. Seules des mains imprimées dans le plâtre et des motifs faits de rassemblements de points ou de figures géométriques simples sont encore bien visibles à certains endroits. L'intérieur des arcs qui séparent les nefs sont décorés à l'occasion par de grands damiers (ill. 2). Brâhîm ibn Slîmân al-Shammâkhî affirme, dans un passage consacré à deux mosquées proches de Tamazdâ, que «l'une d'elles, d'antique origine, appelée la grande mosquée apostolique, est située au milieu des plantations et bâtie en chaux et en pierres. Ses piliers portent des inscriptions qu'aucun de nous ne peut comprendre; les t'olba disent que ces caractères proviennent des populations païennes, antérieures à notre seigneur Moh'ammed. ${ }^{31}$. Cette description fait sans doute référence à la mosquée Ḥawâriyyîn, et non pas à la mosquée Kanîsa de Tamazdâ qui ne comporte aucune inscription ${ }^{32}$.

Contrairement à d'autres lieux de culte dégradés, la mosquée ne présente aucune trace de fréquentation. Hormis quelques rares blocs, utilisés notamment pour l'entrée, qui évoquent le remploi de matériaux antiques, plus rien ne rappelle une église. Il faut noter que de nombreuses mosquées isolées emploient des pierres de taille

29. Al-Shammâkhî, op. cit., p. 287. Les graphies modernes de Tamazdâ sont Temezda, Tmezda ou Tamazda.

30. J.W. Allan, «Some Mosques of the Jebel Nafusa», p. 157 et pl. LXII et LXIII. Nous entendons par «nef» chacun des «couloirs de prière» parallèles au mur de la qibla, qui contient le mihrab.

31. A. Motylinski, Le Djebel Nefousa, p. 93.

32. Voir infra. A. Motylinski, Le Djebel Nefousa, p. 93, n. 2, et R. Basset, «Les sanctuaires du Djebel Nefousa», seconde partie in Journal Asiatique, juillet-août 1899, p. 91, estiment au contraire qu'il s'agit sans doute de la «kanîsa Tamazdâ» évoquée dans la liste Tasmiya mashâhid al-jabal. 
romaines ou byzantines qui ont sans doute été récupérées dans des villas ou des fermes isolées ${ }^{33}$. Le remploi de colonnes antiques est également très répandu en Afrique du Nord, grâce à l'abondance de matériaux antiques disponibles à l'arrivée des musulmans. Les investigations archéologiques menées dans diverses régions de Libye montrent à plusieurs reprises une continuité entre la période byzantine et celle des premiers temps de l'islam, les musulmans ayant réutilisé de nombreux édifices anciens, qu'il s'agisse de bains, d'édifices militaires ou civils. À Berenike, l'actuelle Sidi Khrebish, une église $\mathrm{du} \mathrm{VI}^{\mathrm{e}}$ siècle a été réutilisée à des fins apparemment laïques ${ }^{34}$.

En plus de la mosquée Ḥawâriyyîn de Fursațâ, étudiée ci-après, une autre mosquée des apôtres (masjid al-Hawâriyyîn) est mentionnée dans la première moitié du XII ${ }^{\mathrm{e}}$ siècle à Gafsa, dans le Sud tunisien ${ }^{35}$. Le terme hawâriyyûn désigne dans le Coran (III, 52; V, 111-112; LXI, 14) les apôtres, «auxiliaires, amis, assistants» et est réservé aux compagnons de Jésus ('Îsâ) ${ }^{36}$. Selon le père Joseph Mesnage, ces basiliques dites apostoliques auraient donc pour origine l'un des douze compagnons de Jésus, sans quoi les auteurs arabes et berbères qui les évoquent auraient employé d'autres mots comme celui de kanîsa ${ }^{37}$. L'évangélisation de la Tripolitaine aurait eu lieu pour lui à l'époque apostolique, suite à l'arrivée de plusieurs prédicateurs dans la région, ce que confirmerait un fragment évoquant un certain Archaeus qui était probablement l'évêque de Leptis Magna dans la seconde moitié du II $^{\mathrm{e}}$ siècle, et qui se désigne comme successeur des disciples du Seigneur ${ }^{38}$. Christian Courtois juge irrecevable la tradition des mosquées apostoliques et qualifie de «légende» les propos rapportés à Adolphe de Callasanti Motylinski

33. Islamic Art and Architecture in Libya, Londres, Publication of the Libyan Committee for Participation in the World of Islam Festival, 1976, p. 32.

34. G.R.D. King, «Islamic Archaeology in Libya, 1969-1989», Libyan Studies, 20 (1989), p. 195 et p. 203.

35. Kitâb al-Istibșâr fî̀ 'ajâ'ib al-amșâr, éd. Sa'd Zaghlûl 'Abd al-Hamîd, Alexandrie, Imprimerie de l'Université, 1958, p. 152.

36. Le Coran, trad. Denise Masson, Paris, Gallimard, 1967, p. 807.

37. Père Joseph Mesnage, «Le christianisme en Afrique», Revue Africaine, LVII (1913), p. 392-393. Il rappelle les termes utilisés par les Berbères du djebel: temezguida tahouarit (mosquée apostolique) et temezguida n'h'aouarin (église des apôtres), qui sont les équivalents des mots arabes hawârî (apostolique) et hawâriyyîn (des apôtres).

38. J. Mesnage, «Le christianisme en Afrique», p. 393. 
par Brâhîm ibn Slîmân al-Shammâkhî, estimant que, remontant à la fin du XIX ${ }^{e}$ siècle, ils n'ont aucune valeur. L'existence d'un certain Archaeus qui aurait été évêque de Leptis ne lui paraît pas plus vraisemblable ${ }^{39}$.

\section{LA MOSQUÉE KANÎSA DE TAMAZDÂ}

Tout au contraire, la mosquée Kanîsa - sans doute identique à la «kanîsa Tamazdâ» mentionnée dans la liste Tasmiya mashâhid $a l$-jabal $l^{40}$ - affiche clairement ses origines byzantines ${ }^{41}$. Située dans la steppe à quelques centaines de mètres seulement de la précédente, elle a été décrite par les Américains, qui la nomment «al-Kanîsiyya», puis par Muhammad al-Warfallî. Elle est bâtie en pierres sur un plan carré d'environ 10,5 mètres de côté. La façade est doublée par une extension en pierre, plus basse et peu profonde, qui a été ajoutée pour accueillir la niche du mihrab et l'arcade du mur de qibla, ainsi que la porte d'entrée (ill. 3). Devant cette extension se trouve une double cour entourée par un mur bas, qui comprend une citerne. L'intérieur de la mosquée est divisé en quatre nefs séparées par trois arcades contenant chacune quatre colonnes faites le plus souvent de pierres de taille d'origine romaine. Selon la description des archéologues américains, neuf colonnes semblent romaines et six ont des bases romaines, alors que trois de ces bases gisent à l'extérieur de l'édifice. Les arcs reposent sur des chapiteaux carrés ${ }^{42}$.

Trois photos prises vers 1970 témoignent d'un bâtiment en bon état ${ }^{43}$. À nouveau, la déception est grande de constater que l'édifice s'est considérablement dégradé en ces quelque quarante ans ${ }^{44}$. Le plafond est crevé à un endroit, des blocs taillés gisent

39. Christian Courtois, Les Vandales et l'Afrique, Paris, Arts et métiers graphiques, 1955, p. 77, n. 1.

40. R. Basset, «Les sanctuaires du Djebel Nefousa», p. 372.

41. Il s'agit sans doute des vestiges de basilique byzantine découverts à Tamazdâ. F. Beguinot, Encyclopédie de l'Islam, $2^{\mathrm{e}}$ éd., s.v. Nafûsa, qui évoque de mêmes vestiges à Ițarmisen.

42. J.W. Allan, «Some Mosques of the Jebel Nafusa», p. 157-159; Muhammad S. al-Warfallî, Ba 'ḍ al-âthâr al-islâmiyya bi-jabal Nafûsa fî Lîbyâ, s.l., Mu' assasa Tâwâlt al-thaqâfiyya, 2009, p. 253-272.

43. Voir J.W. Allan, «Some Mosques of the Jebel Nafusa», pl. LXIII et LXIV.

44. Jean Despois, Le djebel Nefousa (Tripolitaine). Étude géographique, Paris, 
en grand nombre aux alentours, et le sol de la salle de prière est recouvert d'une très épaisse couche de terre et de gravats, à tel point qu'on croirait que le sol s'est soulevé (ill. 4-6). Certains fûts de colonnes sont engagés presque à mi-hauteur dans la terre. Une sorte de gigantesque puits a été creusé qui pourrait expliquer la terre de déblai accumulée à l'intérieur de la salle. Selon les ibadites de Tamazdâ qui nous ont conduits à cette mosquée, ce puits est l'œuvre de chercheurs de trésors, qui avaient été intrigués par la visite des archéologues américains et espéraient découvrir un trésor byzantin! L'enduit protecteur recouvrant les murs a souvent totalement disparu, provoquant de nombreux risques d'éboulement. Heureusement, la partie ajoutée par les ibadites pour accueillir le mihrab a été préservée (ill. 5). Comme la mosquée Hawâriyyîn, celle-ci paraît abandonnée et il y a fort à parier qu'elle aura quasiment disparu d'ici peu de temps.

Contrairement à la majorité des mosquées ibadites que nous avons visitées, la salle de prière ne comprend ni inscriptions, ni motifs géométriques. Outre cela, plusieurs éléments différencient ce lieu de culte des autres mosquées du djebel: son plan est carré et non pas rectangulaire, il n'y a aucune trace de cloison délimitant une partie réservée aux femmes, et la qualité de la construction est bien plus grande que ce que l'on observe habituellement. Les pierres de taille qui étaient éparpillées au début des années 1980 aux abords du mihrab - et que l'on ne voit plus aujourd'hui - suggèrent que le sol de l'édifice était jadis recouvert de pierres polies ${ }^{45}$. Si l'on ajoute à ces indices l'extension qui comprend la niche du mihrab et l'entrée, manifestement construite de façon plus fruste que le reste de l'édifice, il nous semble certain qu'il s'agit bien ici d'une ancienne église byzantine, certes rénovée, qui a été adaptée par les ibadites aux besoins de leur culte, et non d'une mosquée construite à partir d'éléments antiques trouvés sur place ${ }^{46}$. Si le terme kanîsa

Larose, 1935, p. 143, signale que la population de Tamazdâ est partagée entre berbérophones ibadites et arabophones malékites. Serait-ce l'une des raisons pour lesquelles la mosquée est moins entretenue que d'autres édifices dans des régions entièrement ibadites? Au contraire, M. al-Warfallî, Ba'd al-âthâr al-islâmiyya, p. 254, note que c'est une des mosquées qui jouit du plus d'estime de la part des habitants.

45. M. al-Warfallî, Ba'd al-âthâr al-islâmiyya, p. 260 et p. 267-269.

46. Selon M. al-Warfallî, Ba'd al-âthâr al-islâmiyya, p. 272, la mosquée remonte au $\mathrm{VIII}^{\mathrm{e}}$ ou au $\mathrm{IX}^{\mathrm{e}}$ siècle, si elle n'est pas plus ancienne. 
fait sans nul doute ici référence à une église chrétienne, il faut noter qu'il peut, dans un contexte juif, s'appliquer à une synagogue ${ }^{47}$. Les toponymes dérivés de kanîsa peuvent aussi désigner des cimetières ou des ruines antiques ${ }^{48}$. Les sources ibadites mentionnent, dans le djebel Nafûsa, le village de Tinkânîṣ ou Tinkanîṣ qui tire sans doute son nom d'une église qui se trouvait là ${ }^{49}$.

\section{LA MOSQUÉE TAGHLÎS DE FURSAṬ̂̂}

Fursațâ ou Fursațâ' est un important village ibadite, mentionné déjà lors d'événements qui concernent le début du $\mathrm{x}^{\mathrm{e}}$ siècle $^{50}$, situé dans la région de Kâbâw (Kabao). La liste Tasmiya mashâhid al-jabal mentionne une «kanîsa Fursațâ ${ }^{51}$ qui indiquerait que le village existait avant la conquête arabe. Pour Tadeusz Lewicki, le toponyme trouverait son origine dans le terme latin-africain forseta qui se rattacherait à la racine signifiant «forcer» ou dans le terme latin-africain foresta qui désigne une forêt ou un hameau ${ }^{52}$. La mosquée Taghlîs est située non loin du village actuel de Fursaṭ̂, près d'un château d'eau ${ }^{53}$. Elle mesure $22 \times 9$ mètres et comprend plusieurs locaux en plus de la salle de prière. De grossiers contreforts ont été ajoutés tout autour du bâtiment, sans doute dans les années soixante. Une inscription en plâtre, déjà tombée lors des investigations américaines, indiquait avoir été faite par le cheikh Sulaymân 'Amr al-'Azzâbî, que nous ne pouvons identifier ${ }^{54}$; une autre notait des réparations apportées à la mosquée en 965/1557-

47. Hady Roger Idris, «Les tributaires en Occident musulman médiéval d'après le mi 'yâr d'Al-Wansharîshî», in Mélanges d'Islamologie dédiés à la mémoire d'Armand Abel, Leyde, Brill, 1974, I, p. 190 et p. 194.

48. Mikel De Epalza, «Les mozarabes, état de la question», Revue des mondes musulmans et de la Méditerranée, 63-64 (1992), p. 44.

49. Al-Bughṭ̂nî, op. cit., p. 138; al-Shammâkhî, op. cit., p. 392. T. Lewicki, Études ibâdites nord-africaines, p. 57.

50. Al-Bughtûrî, op. cit., p. 58 et al-Shammâkhî, op. cit., p. 292.

51. R. Basset, «Les sanctuaires du Djebel Nefousa», p. 372.

52. T. Lewicki, «Une langue romane oubliée de l'Afrique du Nord. Observations d'un arabisant », Rocznik Orientalistyczny, XVII (1953), p. 457-458.

53. Ce château d'eau est visible à l'arrière-plan de l'illustration $n^{\circ} 7$. Cela permet d'imaginer la proximité des deux mosquées Taghlîs et Ḥawâriyyîn.

54. Il s' agit peut-être de «l'agha Slimân al-Azzabi, moudir de Fassâto, l'homme le plus influent et le plus énergique de son pays» qui a renseigné Duveyrier lors de son séjour dans le djebel en 1860. Henri Duveyrier, «Statistique du Djebel- 
$1558^{55}$. Lors de notre visite, nous avons tout d'abord constaté que la mosquée a été à nouveau restaurée, puisqu'un cimentage, bien que déjà fort fissuré, recouvre les contreforts proches de l'entrée. L'intérieur indique qu'elle est régulièrement fréquentée puisque le sol est recouvert de nattes, de couvertures et de coussins et qu'on y voit de la vaisselle, des bouteilles d'eau et un service à thé. La salle de prière est formée de deux nefs et celle sur laquelle donne l'entrée comporte une succession d'arcs pointus caractéristiques. Les parois portent à de nombreux endroits des inscriptions arabes ou des motifs géométriques évoquant le traditionnel décor berbère. Une longue inscription est malheureusement presque illisible. Des morceaux de bois fichés dans le plafond sont destinés à suspendre des Corans. Cette mosquée très allongée et basse, qui s'étend effectivement bien au-delà de la salle de prière, a un aspect particulièrement étrange. Des fragments de poterie datant des $\mathrm{IV}^{\mathrm{e}}-\mathrm{VI}^{\mathrm{e}}$ siècles ont été trouvés dans les environs ${ }^{56}$.

Le terme «taghlîs », dérivé du latin ecclesia, apparaît fréquemment au Maghreb, de même que ses variantes. Al-Muqaddasî, géographe arabe du $\mathrm{X}^{\mathrm{e}}$ siècle, affirme qu'une des villes de la région de Tâhart, la capitale des imams ibadites, se nomme Tâghlîsiyya ${ }^{57}$. De même, à Djerba, l'îlot Guettâya Guebliya, face à Ajim, est appelé «Taghlisia» par les Djerbiens, ce qui montre qu'il y avait sans doute là une église chrétienne ${ }^{58}$. Dans le djebel Nafûsa, les chercheurs américains ont répertorié trois mosquées nommées "Taghlîs » ${ }^{59}$. Un puits situé en dessous du ksar de Nâlût porte le même nom ${ }^{60}$. Plus à l'est, Charles Tissot évoque à la fin du XIX ${ }^{\mathrm{e}}$ siècle les ruines considérables de Tâghlîs ${ }^{61}$. D'autres termes pourraient dériver

Nefousa, montagnes de la Régence de Tripoli», Nouvelles Annales des Voyages, de la Géographie et de l'Histoire, vol. 171 (série 6, tome 27, 1861), p. 133.

55. J.W. Allan, «Some Mosques of the Jebel Nafusa», p. 151 et pl. LIV et LV.

56. J.W. Allan, «Some Mosques of the Jebel Nafusa», p. 151 et p. 169.

57. Al-Muqaddasî, Kitâb Ahsan al-taqâsîm fì ma'rifat al-aqâlîm, éd. Michiel Jan de Goeje, Leyde, Brill, 1967, p. 218.

58. Vermondo Brugnatelli, «Notes d'onomastique jerbienne et mozabite», in K. Naït-Zerrad, R. Vossen et D. Ibriszimow (éd.), Nouvelles études berbères. Le verbe et autres articles, Köln, Rüdiger Köppe Verlag, 2004, p. 35-36.

59. J.W. Allan, «Some Mosques of the Jebel Nafusa», p. 168.

60. A. Motylinski, Le Djebel Nefousa, p. 107. Il s'agit sans doute de la source «'ayn Taghlîs» évoquée par Henri Duveyrier dans Charles Tissot, Géographie comparée de la province romaine d'Afrique, Paris, Imprimerie nationale, 1884-88, II, p. 709, n. 9. Voir aussi T. Lewicki, «Une langue romane oubliée», p. 442-443.

61. Ch. Tissot, Géographie comparée de la province romaine d'Afrique, II, 
du latin ecclesia: ce serait le cas de la mosquée nommée Jilîzat évoquée dans la Tasmiya mashâhid al-jabal et du village d'Ijlâzan cité par al-Shammâkhîî ${ }^{2}$.

\section{LA MOSQUÉE ḤAWÂRIYYîn DE FURSAṬ̂̂}

Les archéologues américains ont décrit une mosquée d'environ 7,8 x 9 mètres, à trois nefs, partiellement en mauvais état, qui comporte une inscription indiquant que la mosquée a été réparée pour la dernière fois en 1312/1894-189563. Sa particularité est d'être voisine, de quelques mètres seulement, d'une autre mosquée entièrement souterraine, à laquelle on accède par une rampe dont les parois sont faites de pierres bien agencées (ill. 7). À notre passage, la rampe d'accès était tellement encombrée de détritus en tous genres qu'il était presque impossible, à moins peut-être de ramper, de pénétrer dans la mosquée. L'autre particularité de la mosquée Ḥawâriyyîn de Fursațâ est d'avoir conservé un grand nombre de motifs décoratifs et d'inscriptions. On y voit notamment une sorte de serpe qui surmonte des triangles. La mosquée semble avoir été récemment cimentée à plusieurs endroits lors de travaux de consolidation et des objets laissés à l'intérieur attestent de sa fréquentation. Les piliers soutenant les arcs qui séparent deux des nefs laissent voir d'anciennes colonnes manifestement antiques (ill. 8). Des blocs de pierre de taille sont également visibles à plusieurs endroits. Il pourrait s'agir ici d'un bâtiment qui a été reconverti.

Jean Despois a mentionné, dans les années trente, deux petites agglomérations en ruine situées à l'ouest de Fursațâ, Lahourîn (correspondant à al-ḥawâriyyîn) et Taghlis, dont les noms indiquent qu'elles accueillaient certainement des églises ${ }^{64}$. Il s'agit sans doute des deux localités, aujourd'hui totalement disparues, qui entouraient les mosquées Ḥawâriyyîn et Taghlîs.

p. 709. Ce sont sans doute les ruines appelées «Henchir Taglissi » par Y. Modéran, Les Maures et l'Afrique romaine, carte p. 284.

62. R. Basset, «Les sanctuaires du Djebel Nefousa», p. 373; al-Shammâkhî, op. cit., p. 384; T. Lewicki, Études ibâdites nord-africaines, p. 57.

63. J.W. Allan, «Some Mosques of the Jebel Nafusa», p. 151 et pl. LIII.

64. J. Despois, Le djebel Nefousa, p. 265; T. Lewicki, Études ibâdites nordafricaines, p. 57. 


\section{Conclusions}

Ces quatre lieux de culte, dont deux semblent voués à une disparition prochaine, suscitent un grand nombre de questions. Comme il a été dit plus haut, il est probable que les habitants du djebel, pour la plupart chrétiens, ont été convertis massivement à la doctrine ibadite par des prédicateurs locaux dont nous avons conservé deux noms, 'Umar ibn Îmkatan qui a appris la doctrine sur la côte libyenne et Ibn Maghțîr al-Nafûsî qui l'a étudiée à Bașra. En 140/757-758, peu après le retour d'Orient des «porteurs de science», Abû l-Khatṭâb al-Ma âfirî est proclamé imam. À cette époque, la grande majorité des Berbères du djebel ont adopté l'ibadisme et rejoignent le combat de l'imam et de ses successeurs ${ }^{65}$. La première question qui se pose est de savoir s'il subsiste alors des groupes de chrétiens dans les montagnes. L'existence de chrétiens en Tripolitaine est attestée jusqu'au début du $\mathrm{XI}^{\mathrm{e}}$ siècle: en effet, on a découvert dans la nécropole d'En-Gila, au sud de Tripoli, une douzaine de textes latins dont les dates s'échelonnent entre 945 et $1003^{66}$. En ce qui concerne le djebel proprement dit, seules les sources ibadites sont à même de nous renseigner, mais on n'y trouve somme toute que peu de renseignements. Les historiens décrivent comment une chrétienne s'est convertie après son mariage avec un ibadite: Abû Yahyâ Azdâlî envoya chercher un chrétien avec lequel il était engagé dans des affaires pour manger du raisin. Le chrétien arriva avec ses filles qui étaient très belles, ce qui l'étonna. Le chrétien lui confirma que chez eux, tout le monde partageait cette beauté et ajouta que s'il était licite selon la religion (ibadite) qu'Abû Yaḥyâ Azdâlî épouse une de ses filles, il lui en donnerait une en mariage. Ce dernier choisit alors Umm al-Khatțâb, il l'épousa, puis lui dit de se convertir à l'islam ou de rentrer chez les siens, ce qui était

65. Comme le souligne Elizabeth Savage, A Gateway to Hell, a Gateway to Paradise, the North African Response to the Arab Conquest, Princeton, The Darwin Press, 1997, p. 100, les Berbères rejoignent surtout le combat contre les armées arabes et sont sans doute animés par des motivations plus politiques que religieuses, puisque l'enseignement qu'ils ont reçu des prédicateurs doit se limiter aux notions élémentaires de la doctrine.

66. William Seston, «Sur les derniers temps du christianisme en Afrique», Mélanges d'archéologie et d'histoire de l'école de Rome, LIII, fasc. I-IV (1936), p. 103. Pour A. Di Vita, «La diffusione del cristianesimo», p. 139, des noyaux chrétiens ont subsisté en Tripolitaine jusqu'au milieu du $\mathrm{XI}^{\mathrm{e}}$ siècle. 
interdit et honteux chez les chrétiens. Umm al-Khattâab choisit alors de se convertir et fit ses ablutions ${ }^{67}$. Abû Yahyâ Azdâlî est classé parmi les savants de la cinquième tabaqa (200-250/c. 815-865) et cette histoire se déroule donc probablement dans la première moitié du IX ${ }^{\mathrm{e}}$ siècle.

Al-Shammâkhî évoque à la même époque un certain Abû Yahyâ Takasnît: parmi ses miracles les plus étonnants, il avait une mère chrétienne dont il ne tétait pas le sein quand elle avait bu du vin et goûté à ce qui était interdit ${ }^{68}$. Toujours à cette époque, 'Amrûs ibn Fatḥ al-Masâkanî possédait un esclave chrétien ${ }^{69}$. Un texte fait mention des richesses des chrétiens que les calamités n'atteignent $\operatorname{pas}^{70}$. Enfin, nous savons que la famille d'un des plus célèbres gouverneurs du djebel, Abû Manșûr Ilyâs (m. à la fin du IX ${ }^{\mathrm{e}}$ siècle), a conservé des coutumes chrétiennes comme le prouve ce texte d'al-Darjînî: "Les cheikhs ont mentionné que dans la famille d'Abû Manșûr et sa descendance, trois choses n'avaient ni cessé ni changé depuis qu'ils avaient abandonné le christianisme et étaient revenus à la religion islamique, et cela jusqu'à l'époque à laquelle on en a fait mention. Ce sont l'intégrité morale, la semence de blé et la reproduction des moutons; la première est liée à l'appel (religieux) précédent, la seconde et la troisième à la crainte de Dieu et à la réserve, tout cela avec l'aide et l'approbation de Dieu ToutPuissant. $»^{71}$.

Le célèbre savant ibadite Abû 'Abd Allâh Muḥammad ibn Bakr (m. 440/1048-1049), originaire du djebel - ce qui lui vaut d'être connu sous le nom de Nafûsî -, suscite ce commentaire: «quel émerveillement que ce Nafûsî et ses compagnons qui sont comparables aux apôtres vis-à-vis de Jésus, que le salut soit sur lui. $\gg^{72}$. Ce passage est à mettre en rapport avec la fondation par Abû 'Abd Allâh Muḥammad ibn Bakr de la ḥalqa, qui s'apparentait, au début tout au moins, à une institution monastique ${ }^{73}$. Dans le texte

67. Al-Bughṭ̂rî, op. cit., p. 152; al-Shammâkhî, op. cit., p. 407-408.

68. Al-Shammâkhî, op. cit., p. 393.

69. Al-Shammâkhî, op. cit., p. 372.

70. Al-Bughtûrî, op. cit., p. 38; al-Shammâkhî, op. cit., p. 457.

71. Al-Darjînî, op. cit., p. 329-330. Cet extrait figure déjà dans Siyar al-mashâ'ikh, p. 542, mais sous une forme tronquée qui le rend incompréhensible.

72. Abû Zakariyyâ', op. cit., p. 259; al-Darjînî, op. cit., p. 186.

73. Voir V. Prevost, «Genèse et développement de la hạalqa chez les ibâdites maghrébins», Acta Orientalia Belgica, XIX (2006), p. 109-124. 
anonyme Siyar al-mashâ'ikh, un savant évoque les apôtres qui s'enquièrent auprès de Jésus, «l'envoyé de Dieu, l'esprit de Dieu », de la personne qu'ils devront accompagner après sa disparition; Jésus leur répond qu'ils devront suivre celui qui leur sera désigné par Dieu ${ }^{74}$. Le même texte évoque une tradition selon laquelle «celui qui nourrit un chef de famille est comparable à celui qui nourrit Jésus fils de Marie ${ }^{75}$. Dans le djebel Nafûsa, la plus remarquable inscription trouvée dans la mosquée de Sharûs - antérieure à la destruction de la ville vers 1100 - concerne l'égalité des révélations faites aux musulmans, aux juifs et aux chrétiens ${ }^{76}$. Cette inscription reprend le verset coranique (II, 136) qui affirme l'égalité des vérités divines révélées d'une part à Muhammad et d'autre part aux patriarches juifs et aux prophètes : «Dites : Nous croyons en Dieu, à ce qui nous a été révélé, à ce qui a été révélé à Abraham, à Ismaël, à Isaac, à Jacob et aux tribus, à ce qui a été donné à Moïse et à Jésus ; à ce qui a été donné aux prophètes, de la part de leur Seigneur. Nous n'avons de préférence pour aucun d'entre eux; nous sommes soumis à Dieu. $\gg^{77}$. Tous ces exemples montrent bien que d'une part, les ibadites étaient soucieux de rester en bons termes avec les communautés chrétiennes qui indubitablement subsistaient dans le djebel, même si elles étaient extrêmement réduites, et que d'autre part, ils faisaient à l'occasion référence à leur ancienne culture chrétienne, en se référant notamment aux apôtres ${ }^{78}$.

Il est probable que les églises byzantines ont été reconverties petit à petit, et peut-être parfois bien longtemps après l'islamisation

74. Siyar al-mashâ'ikh, p. 741. Al-Darjînî, op. cit., p. 451, donne la même tradition, évoquant «Jésus fils de Marie, esprit de Dieu».

75. Siyar al-mashâ'ikh, p. 596.

76. N.M. Lowick, «The Arabic Inscriptions on the Mosque of Abû M'arûf at Sharwas », Libyan Studies, 5 (1974), p. 15-16.

77. Le Coran, trad. Denise Masson, Paris, Gallimard, 1967, p. 26.

78. Une anecdote qui se déroule manifestement dans la première moitié du $\mathrm{X}^{\mathrm{e}}$ siècle montre que les sunnites avaient également à cœur de maintenir de bonnes relations avec les chrétiens: à Tripoli, chrétiens et musulmans se querellent à propos d'une pierre que les chrétiens ont utilisée pour renforcer l'un des angles de leur église, prétendant qu'elle leur appartient de longue date. Les musulmans soutiennent au contraire qu'elle provient d'une mosquée en ruine. Un savant sunnite s'adresse à la pierre, la pressant de se manifester si les musulmans ont dit vrai, et la pierre tombe, entraînant l'effondrement d'un angle de l'église. Le savant dit alors aux musulmans d'emporter leur pierre, et aux chrétiens de rebâtir leur église. Al-Mâlikî, Riyậd al-nufûs fî tabaqât 'ulamâ' al-Qayrawân wa-Ifrîqiya, éd. Bashîr al-Bakkûsh, Beyrouth, Dâr al-gharb al-islâmî, 1994, II, p. 391. 
de la région ${ }^{79}$. Les chrétiens ont certainement continué à occuper leurs églises jusqu'à la disparition de leurs communautés. Un texte ibadite qui fait autorité dans le Mzab du XIX ${ }^{\mathrm{e}}$ siècle, le Kitâb al-Ahkâm, établit les règles à ce sujet: «On ne leur [aux chrétiens] laissera pas créer de nouvelles églises. On ne les empêchera pas de pratiquer dans les églises pour lesquelles ils ont payé la djezia; mais on leur interdira d'y ajouter de nouvelles constructions et si elles tombent en ruines, on les empêchera de les rebâtir ${ }^{80}$. Les églises désertées ont sans doute été réoccupées par les ibadites, par attachement à une place sacrée vénérée autrefois par leurs ancêtres. On peut estimer que lorsque ces églises étaient en ruine, les ibadites ont construit leurs mosquées à la même place, par respect vis-à-vis de ce lieu saint. Ainsi, les Aït Antar de N'Goussa, dans la région de Ouargla en Algérie, se disent descendants des Romains convertis à l'islam et affirment que les ruines d'une de leurs mosquées sont situées sur les ruines d'une antique église romaine ${ }^{81}$. De même à Talmîn, dans le Sud tunisien jadis ibadite, la mosquée du XIX ${ }^{e}$ siècle aurait remplacé une basilique chrétienne ${ }^{82}$. Cela pourrait expliquer selon nous que certaines mosquées portent des noms évoquant le christianisme alors que l'on n'y trouve plus la moindre trace d'église. Seul le souvenir de la place autrefois sacrée a été conservé. L'historien ibadite al-Shammâkhî (m. 1522) raconte ainsi s'être rendu avec un savant à «l'endroit des martyrs » au village d'Amsîn, où l'on voyait des traces de sang sur un rocher. Il essuya ce sang avec son vêtement, lequel fut taché. Son compagnon expliqua alors qu'il s'agissait du sang de trois martyrs; deux d'entre eux étaient de «la religion de 'Îsâ (Jésus)», donc chrétiens, et avaient été tués

79. Dans les territoires conquis, les musulmans s'appropriaient de nombreuses églises, qu'il était tout naturel de transformer en mosquées, ces sanctuaires survivant au changement de religion. Voir Johs. Pedersen, Encyclopédie de l'Islam, $2^{\mathrm{e}}$ éd., s.v. Masdjid, sur l'islamisation de monuments chrétiens. Au lieu-dit «Djendouba», non loin de l'actuelle Gharyan à l'est du djebel, ont été découvertes en 1903 les ruines d'une basilique que les Arabes venaient de mettre au jour pour la reconvertir en mosquée, transformation demeurée inachevée. Henri Méhier de Mathuisieulx, Rapport sur une mission scientifique en Tripolitaine, Paris, Imprimerie nationale, 1904, p. 16-18.

80. A. Motylinski, «Notes historiques sur le Mzab, Guerrara depuis sa fondation», Revue Africaine, XXVIII (1884), p. 437.

81. Alain Romey, Histoire, mémoire et sociétés. L'exemple de N'Goussa: oasis berbérophone du Sahara (Ouargla), Paris, L'Harmattan - Awal, 1992, p. 76.

82. Ch. Tissot, Géographie comparée de la province romaine d'Afrique, II, p. 702 . 
de manière injuste au nom du monothéisme soixante ans avant l'envoi du Prophète (c'est-à-dire vers le milieu du vi siècle); le troisième martyr, originaire du djebel Demmer (en Tunisie), était en train de prier à cet endroit lorsqu'il fut tué injustement. Le savant ajouta que le sang de ces trois martyrs, resté sur le rocher malgré le ruissellement des eaux de pluie, était pur ${ }^{83}$. Le lieu de ce martyre est peut-être à mettre en rapport avec la «kanîsa Masîn» évoquée dans la Tasmiya mashâhid al-jabal ${ }^{84}$. Les Berbères du djebel sont restés de la même façon fidèles à quantité de lieux qu'ils vénéraient lorsqu'ils étaient encore païens, et ces lieux sont soigneusement énumérés dans les sources ibadites ${ }^{85}$.

Ainsi, s'il paraît certain que la mosquée Kanîsa de Tamazdâ est une ancienne église transformée en mosquée par les ibadites, s'il est possible que la mosquée Hawâriyyîn de Fursatâ ait connu le même destin, la plupart des mosquées du djebel Nafûsa portant des noms faisant référence au christianisme n'ont sans doute rien à voir avec des lieux de culte chrétiens reconvertis à l'islam. Bâties à l'emplacement d'une ancienne église ou sur un lieu associé au christianisme, leur nom marque simplement le souvenir du passé chrétien de la région.

8 hameau de la Taillette

7911 Frasnes-lez-Anvaing

Belgique

virginie.prevost@skynet.be

83. Al-Shammâkhî, op. cit., p. 770 (l'éd. donne Amîn). Pour T. Lewicki, Études ibâdites nord-africaines, p. 53, ces martyrs étaient des missionnaires chrétiens orthodoxes venus de Sabratha ou d'un autre centre chrétien du littoral tripolitain, qui ont été attaqués par la population païenne, juive ou donatiste habitant ce coin du djebel. Les ruines d'Amsîn étaient encore visibles au début des années trente dans l'agglomération moderne d'El Kherba. J. Despois, Le djebel Nefousa, p. 248.

84. R. Basset, «Les sanctuaires du Djebel Nefousa», p. 373.

85. Voir notamment la liste Tasmiya mashâhid al-jabal dans R. Basset, «Les sanctuaires du Djebel Nefousa», p. 372-373. À ce sujet, T. Lewicki, «Survivances chez les Berbères médiévaux d'ère musulmane de cultes anciens et de croyances païennes », Folia Orientalia, VIII (1967), p. 13-18 et p. 28-33. 

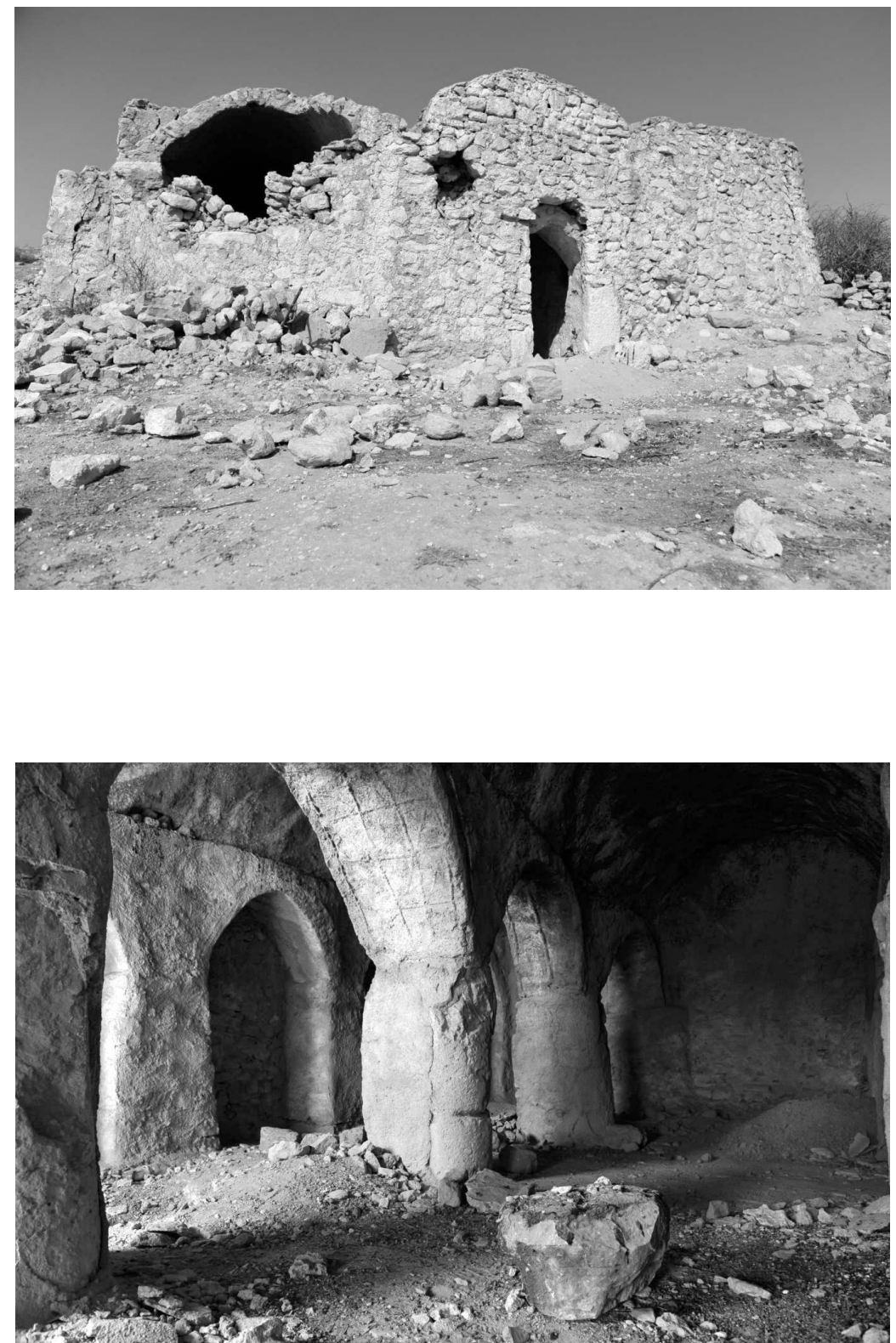

1 et 2. La mosquée Ḥawâriyyîn de Tamazdâ - (C) Axel Derriks 

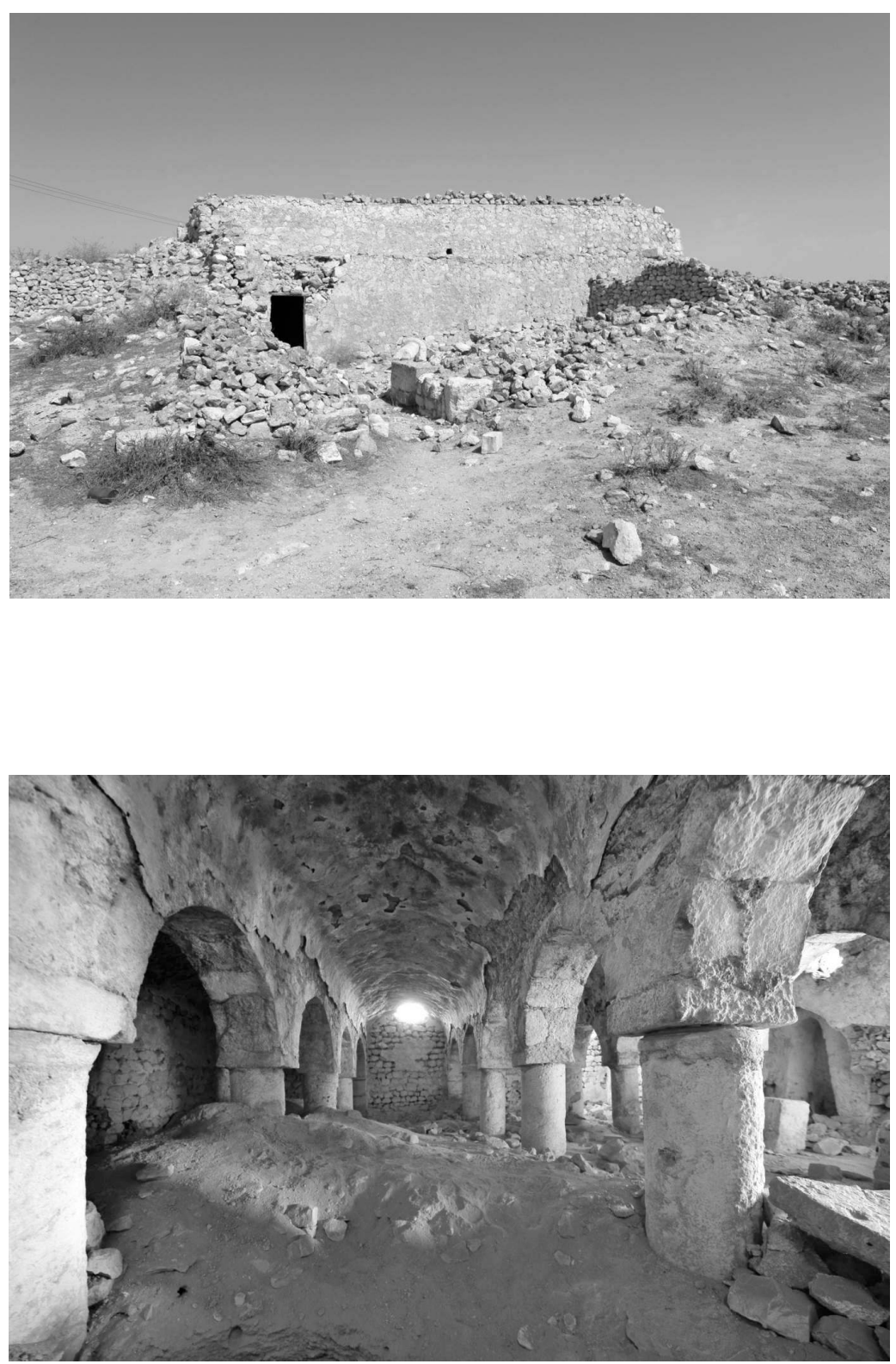

3 et 4. La mosquée Kanîsa de Tamazdâ - (C) Axel Derriks 

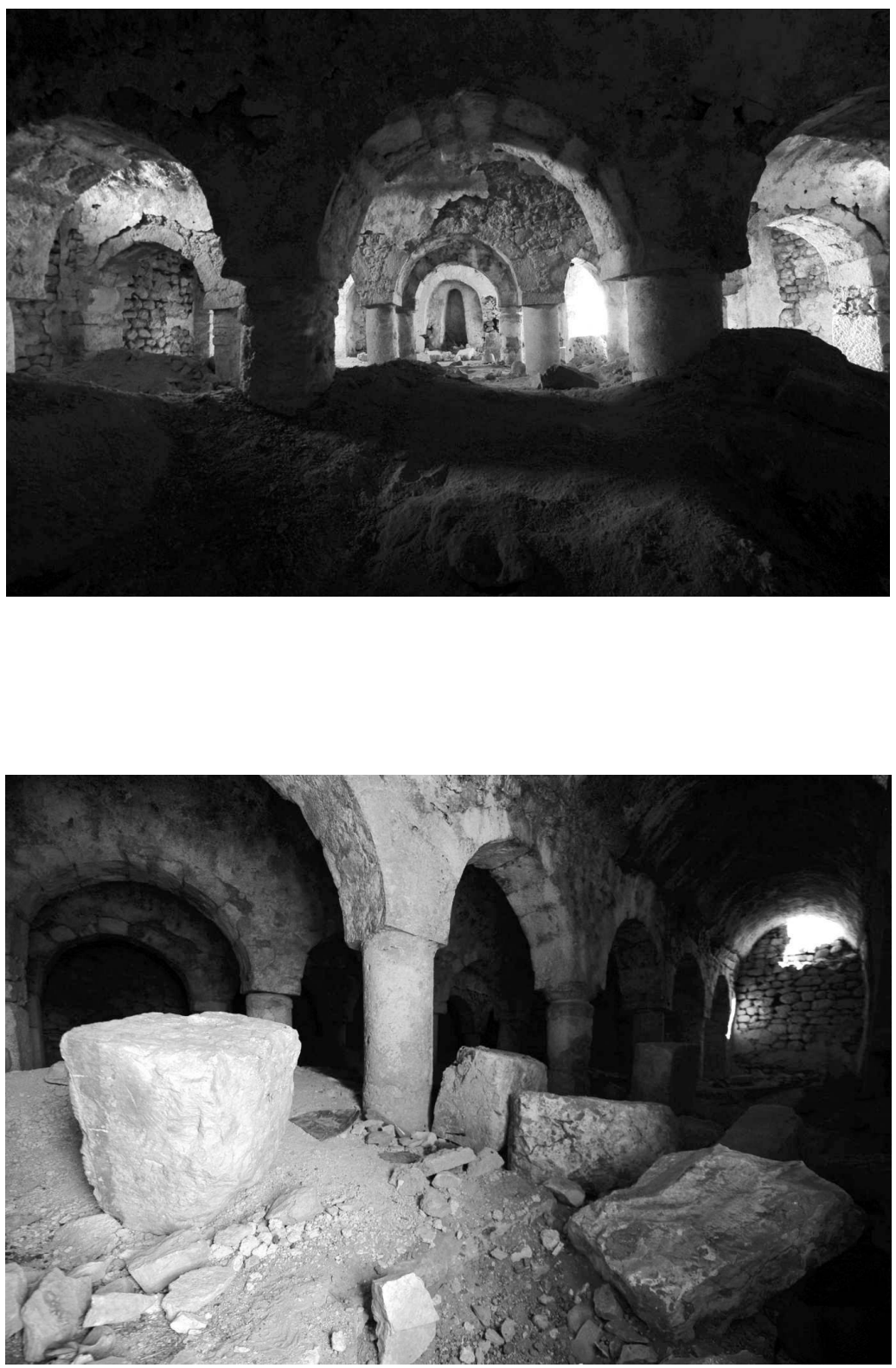

5 et 6. La mosquée Kanîsa de Tamazdâ - C C Axel Derriks 


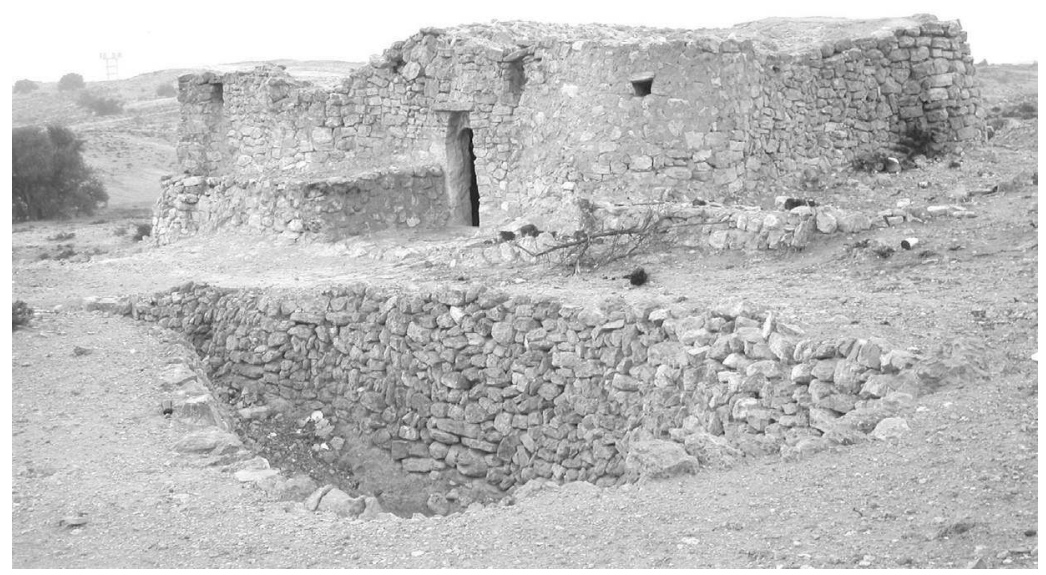

7. La mosquée Hawâriyyîn de Fursațâ - (C) Virginie Prevost

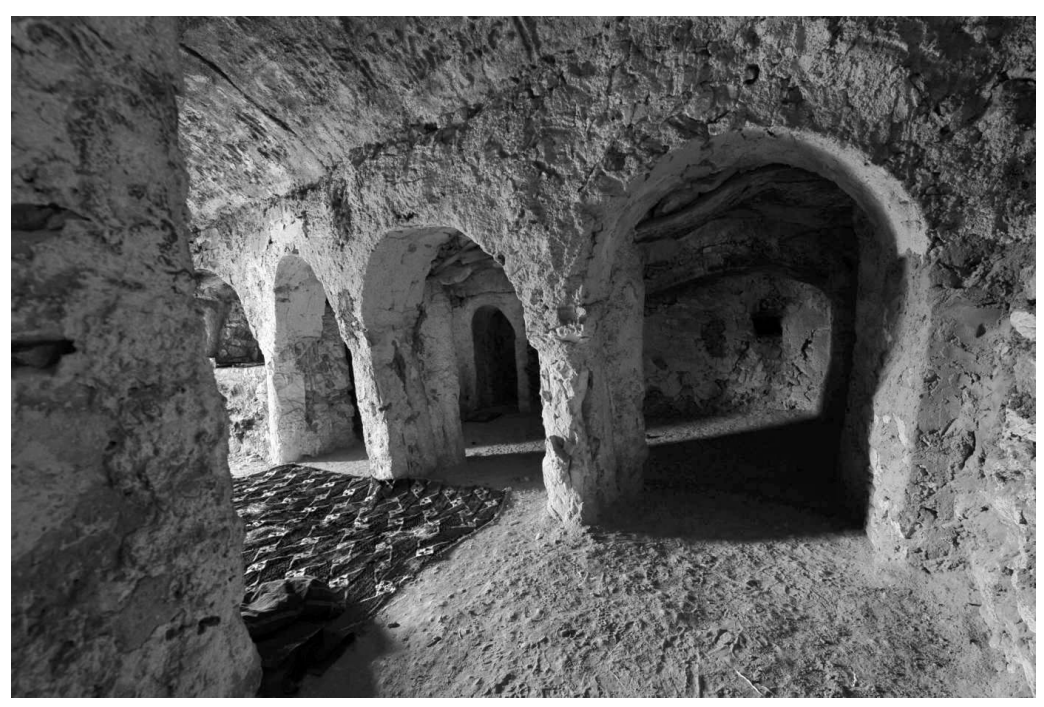

8. La mosquée Hawâriyyîn de Fursaṭ̂ - (C) Axel Derriks 